Cadernos Walter Benjamin 20

\title{
AS ILUMINAÇÕES LIBERTÁRIAS DE WALTER BENJAMIN EM O SURREALISMO
}

Matheus Silveira dos Santos

\section{RESUMO}

Trata-se de analisar o ensaio "O Surrealismo: $O$ último instantâneo da inteligência europeia", de Walter Benjamin, publicado em fevereiro de 1929 na revista Literarische Welt. $O$ pensamento benjaminiano configura uma profunda análise do desenvolvimento dos princípios do surrealismo enquanto movimento estético e político. A pretensão é o estudo de alguns conceitos fundamentais sob os quais o ensaio se constrói, tal como a embriaguez, a iluminação profana e a aproximação do surrealismo com o comunismo e o anarquismo. Para uma melhor compreensão do movimento em seu desdobramento prático-teórico, serão abordados outros ensaios publicados pelos surrealistas na revista Le Libertaire (jornal da Federação Anarquista). Os ensaios contêm uma profunda análise sobre as vias políticas percorridas pelo movimento na Europa do século $X X$, período entre guerras caracterizado pelo nacionalismo emergente e a ascensão do nazi-fascismo. O surrealismo, contra essa onda conservadora, apresenta uma questão política e traça uma questão importante para esta pesquisa: "o que faríamos nós com uma arte que não mudasse a vida?". Para que sejam melhor compreendidos os elementos revolucionários e libertários do surrealismo, assim como os meios que esse movimento forneceu para mudar o mundo,é de grande valor interpretar os conceitos benjaminianos de embriaguez e iluminação profana; em suma, este é o foco central desta pesquisa.

Palavras-chave: Surrealismo. Embriaguez. Iluminação profana. Anarquismo

\section{THE LIBERTARIAN ENLIGHTENMENTS OF WALTER BENJAMIN IN THE SURREALISM}

\begin{abstract}
We analyze the essay "Surrealism: The Last Snapshot of the European Intelligentsia", by Walter Benjamin, published in February 1929 in the journal Literarische Welt. Benjamin's thought configures a deep analysis on the development of the principles of Surrealism, as an aesthetical and political movement. The intent is to study some fundamental concepts from which the essay constructs itself, such as intoxication, profane illumination and the pairing of Surrealism with Anarchism. Towards a better understanding of the movement in its practic-theoretical branch, we will approach other essays published by Surrealists in the review Le Libertaire (a journal edited by the Anarchist Federation). The essays contain a profund analysis on the political paths the movement has taken in 20th century Europe, an interwar period marked by burgeoning nationalism and the rise of nazi-fascism. Surrealism, against this
\end{abstract}

Bacharel em Filosofia e graduando em licenciatura em Filosofia pela UNIFESP.

Pesquisador financiado pela CNPq. Brasileiro, residente em São Paulo-SP. Email: 
conservative tide, presents a political issue and delineates an important question for this work: "what would we do with a kind of art that did not alter life?". So that the revolutionary and libertarian elements of Surrealism are best understood, as well as the means this movement has provided to change to world, it is invaluable to interpret Benjamin's concepts of intoxication and profane illumination. The essay will reflect its own time, which is a period of transition in Benjamin's work as a critic, when the philosopher will reformulate the concept of critique. To understand the politization of the movement, it is fundamental to shed light on its historicity. According to Adorno, History is inherent to aesthetical theory, and the critical theory of art tries to enlighten the historicity of aesthetical theory. In this research, we seek to outline the historical framework of surrealism and stick to the political path that the movement has followed. The surrealists wished to change life with the concepts of profane enlightenment and inebriation contained in the essays of Benjamin. After clarifying the concepts of profane illumination and inebriation, this work aims to study the proximity of surrealism with anarchism, and to that end the following books were used: Theory of vanguard, specifically the chapter on vanguard and engagement; the book Surrealism and anarchism; some of the Theses on the concept of History, by Benjamin, aided as they show the author's antifascist viewpoint and point to a libertarian horizon. Further, we investigate Benjamin's meaning behind "mobilizing the energies of inebriation towards revolution." In summary, that is the central focus of this paper.

Keywords: Surrealism. Intoxication. Profane illumination. Anarchism. Liberty

\section{INTRODUÇÃO}

Publicado em fevereiro de 1929 por Walter Benjamin na revista Literarische Welt, o ensaio O Surrealismo situa-se no fim da primeira fase do Surrealismo. Este ensaio remete ao político no seio de uma estética. As teorias estéticas, como a teoria da vanguarda, são marcadas pela época em que surgiam: o Surrealismo, tema deste artigo, nasce no século $X X$, período que assistiu a uma grande revolução tecnológica, industrial, urbana e cultural; ademais, emerge o nacionalismo e o nazifascismo entra em ascensão. Esse ensaio reflete o seu próprio tempo, e, com isso, o período de transição do trabalho de Benjamin como crítico, quando o filósofo começa a repensar qual o papel do intelectual e a reformular o próprio conceito de crítica. Para compreender a politização do movimento, é fundamental esclarecer sua historicidade. Segundo Adorno, a história é inerente à teoria estética, e a teoria crítica da arte se esforça no sentido de elucidar a historicidade da teoria 
estética (BÜRGUER, 2012, 45). Nesta exposição, pretendo traçar o contexto histórico do Surrealismo e me ater ao caminho político que o movimento percorreu.

Os surrealistas desejavam transformar a vida, e este ensaio busca vincular o desejo de mudar a vida com os conceitos de iluminação profana e embriaguez presentes no ensaio de Benjamin. Após esclarecer possíveis significados desses citados conceitos, em um segundo momento,este ensaio visa aproximar o Surrealismo ao Anarquismo. Os surrealistas encontraram a necessidade de politizar seu movimento diante da hostilidade da burguesia às manifestações de liberdade espiritual, e, segundo Benjamin, foi essa hostilidade que impeliu o Surrealismo para a Esquerda. Pretendo elucidar os tais conceitos de embriaguez e iluminação profana a fim de esclarecer 0 significado do que Benjamin quis dizer com "mobilizar para a revolução as energias da embriaguez", de modo explanar melhor o caminho necessário a ser percorrido para melhor compreensão da trajetória de politização do movimento. Com o intuito de transformar a aspereza do real em uma configuração especial, o Surrealismo subverte a banalidade da vida, segundo Michel Löwy:

[...] um movimento de revolta do espírito e uma tentativa eminentemente subversiva de re-encantamento do mundo, isto é, de restabelecer, no coração da vida humana, os momentos "encantados" apagados pela civilização burguesa: a poesia, a paixão, o amorlouco, a imaginação, a magia, o mito, o maravilhoso, o sonho, a revolta, a utopia. Ou, se assim o quisermos, um protesto contra a racionalidade limitada, o espírito mercantilista, a lógica mesquinha, o realismo rasteiro de nossa sociedade capitalista industrial, e a aspiração utópica e revolucionária de 'mudar a vida'. (LÖWY, 2002, p. 9)

A transformação da realidade e a ideia de revolução das formas de existência aparecem nos estudos de Benjamin sobre o Surrealismo e conduzem ao conceito de iluminação profana. Diz-se iluminação, pois se trata de uma espécie de revelação, fora do universo religioso, que permite ao sujeito ter acesso a uma nova forma de existência. Revelação esta que permitiria ao sujeito um novo olhar para o seu tempo, o que, por fim, poderia revelar vias que induziriam à transformação da realidade, em uma tentativa de reencantar um mundo marcado pelo mal-estar do pós-guerra e pela civilização burguesa.

Bacharel em Filosofia e graduando em licenciatura em Filosofia pela UNIFESP.

Pesquisador financiado pela CNPq. Brasileiro, residente em São Paulo-SP. Email: 
O Surrealismo, para além do domínio estético, buscaria a transformação da vida, questão que transluz no ensaio de Benjamin. Esta é a maneira como qual ele passa de um movimento literário para um movimento político-, portanto, uma obra com uma função social. Assim, o movimento surrealista pretende reencontrar a realidade em sua espessura total, trazendo a ideia de sonho não como algo descolado da realidade, mas como algo que amplia a realidade. Benjamin observa no ensaio $O$ Surrealismo que, para os surrealistas, "a vida parecia ser digna de ser vivida apenas quando se dissolvia, em cada um, o limiar entre o sono e a vigília" (BENJAMIN, 2012, 22). Ou seja, para o filósofo, essa ideia permitiria que imagem e som se interpenetrassem em uma exatidão automática de forma tão venturosa que não sobraria nenhuma fresta para inserir o que é chamado de "sentido". No intuito de unir duas realidades aparentemente distantes, os surrealistas possuíam a ambição de superar as oposições artificiais, como o sonho e a revolução, uma vez que o Surrealismo visa abolir a oposição tradicional entre a ação e a palavra, sonho e realidade. Jean Schuster, escritor e poeta francês considerado elemento importante do movimento surrealista, dá ensejo à discussão sobre a insuficiência da realidade para os surrealistas. Schuster também escreve sobre sono e vigília, como pode ser observado em seu comentário abaixo:

\begin{abstract}
O sonho não é o contrário da realidade. Ele é um aspecto real da vida humana, assim como a ação; e um e outra, bem longe de se excluírem, se completam. Mas, este aspecto, negligenciado ou voluntariamente relegado ao plano das superstições perigosas pela civilização atual (a das casernas, das igrejas e das delegacias contém os fermentos de revolta mais violentos por serem mais profundamente humanos, isto é, profanos). (COELHO, 1990, p.45)
\end{abstract}

Benjamin articula que as características da iluminação profana "são estranhamente associadas à dialética da embriaguez" (BENJAMIN, 2012, 25). A embriaguez estética não seria produzida apenas pelo uso de narcóticos, mas estaria inserida em uma espécie de desregramento dos sentidos que Rimbaud preconizava, e pode ser considerada como uma forma de apreender a realidade com outro olhar. Uma das formas de se pensar sobre a embriaguez é refletir sobre o significado da deriva: o flâneur é um derivante que experimenta a realidade de outra forma. Esse termo vem com o significado de errante ou 
caminhante - Benjamin chama os flâneurs "botânicos do asfalto" (BENJAMIN, 2015, 39). Em seu livro sobre Charles Baudelaire e a modernidade, o autor observa a poesia de Baudelaire e cita o flâneur como um arquétipo da experiência moderna nas grandes metrópoles: trata-se de um espectador do mundo urbano moderno, que observa a maneira como "a cidade muda mais rapidamente que um coração humano" (BENJAMIN, 2015, 209). Temos exemplos do que é a experiência do flâneur em The Man of the Crowd de Edgar Allan Poe, ou em Les foules de Baudelaire; por meio dessas obras é possível extrair algumas características do flâneur: um deambulante de passos lentos, com matizes de melancolia em seus movimentos e que percebe a cidade ao seu redor como um belo quadro a ser contemplado. Ele experimenta a vida em sua inesgotável riqueza de variações e, assim, tenta reencontrar o que há de maravilhoso no cotidiano envolto pelo movimento maquinal e frenético das multidões. Löwy observa em seu livro $A$ estrela da manhã que o derivante experimenta uma embriaguez que devolve sua liberdade, pois não está entregue aos mesmos passos da racionalidade instrumental que busca sempre uma finalidade - igualmente essa uma forma de embriaguez. A embriaguez, para Benjamin, é também uma relação mágica do homem antigo com o cosmos. Essa relação pode ser encontrada no texto "A caminho do planetário", do livro Rua de mão única, de Benjamin, onde o autor discorre sobre o vínculo que teria se perdido na modernidade outrora. Sobre isso, Benjamin expõe: "A Terra pertencerá unicamente àqueles que vivem das forças dos cosmos" (BENJAMIN, 2012, 70). O que se pode interpretar disso é que 0 trato antigo com o cosmos se cumpre na embriaguez, e que somente na comunidade o ser humano poderia se comunicar em embriaguez com 0 cosmos. Tal experiência (Erfahrung) teria sido perdida na modernidade a partir da ascensão da técnica e da racionalidade instrumental. Haveria algum resquício daquela experiência cósmica antiga na contemporaneidade? Teria Benjamin reencontrado esse elo perdido no Surrealismo? Seria possível concluir que este movimento dispõe desta experiência cósmica? Essas indagações precisam ser pensadas com afinco. Para os surrealistas, era válida uma máxima da política poética: "Mobilizar para a revolução as energias da 
embriaguez"; ou seja, a embriaguez não consistiria meramente na ingestão de narcóticos, como já mencionado. O haxixe e o ópio poderiam servir de propedêutica, mas a embriaguez benjaminiana se dá em uma "iluminação profana, de inspiração materialista e antropológica". lluminação profana, pois como André Breton afirma em Qu'est-ce que le surréalisme? de 1934 que "o Surrealismo uma é certa predisposição não a transcender o real, mas a aprofundá-lo, a tomar uma consciência cada vez mais clara e ao mesmo tempo cada vez mais apaixonada do mundo sensível". Isso também faz alusão à "revolta amarga e apaixonada contra o catolicismo em cujo bojo Rimbaud, Lautréamont e Apollinaire engendraram o surrealismo" (BENJAMIN, 2012, 23).

A revelação que a iluminação profana produz seria uma opção não religiosa no campo da subjetividade capaz de indicar as vias de revolucionar a realidade e a vida. O Surrealismo trouxe a ideia de uma mitologia moderna alternativa e profana ao pensamento religioso: "a atração dos surrealistas pelo mito deve-se também ao fato de constituir [...] uma alternativa profana ao domínio religioso sobre o universo do não racional" (LÖWY, 2015, 201). Por meio do pensamento mitológico e subjetivo o Surrealismo pretende reencontrar o maravilhoso no cotidiano e permitir assim outra relação com a vida, a partir de uma incursão pelo subjetivo e pela errância. O "Prefácio para uma mitologia moderna", do livro O Camponês de Paris de Louis Aragon cria uma antítese ao Discurso do método de René Descartes. Esse Prefácio, ao subverter a lógica cartesiana e ocidental, sugere uma mitologia moderna, uma nova ciência e uma epistemologia que é própria da experiência surrealista. Aragon mostra a importância do erro para a evidência, pois a verdade supõe o erro: "compreende-se a luz apenas pela sombra" (ARAGON, 1996, 41). A nova dimensão de significações que é produzida por essa mitologia moderna traz novas revelações e permite a assimilação de outra forma de existência. As esfinges de $O$ Camponês de Paris colocam ao leitor questões que permitem conhecer a sua própria interioridade. A mitologia moderna relaciona-se com a iluminação profana, portanto, pois ambas apontam outro olhar para a realidade e sugerem uma revolução em um tempo de crise marcado pelo processo civilizatório moderno ocidental. Assim, o choque gerado pelas questões das 
esfinges modernas traz uma revelação que permitiria vir à tona uma nova visão de mundo. O autor, portanto, critica assim o racionalismo e o cartesianismo, e sugere uma maneira de ressignificar a existência a partir do encontro do maravilhoso no cotidiano e da criação de uma mitologia moderna. Essa iluminação é chamada de profana, portanto, pois pretende libertar o homem da mitologia religiosa, indicando a possibilidade de uma transcendência que é imanente ao sujeito, fora do domínio religioso e dentro do cotidiano e da vida do próprio sujeito. Neste sentido, a iluminação profana permitiria uma nova experiência da realidade, e é nesse sentido de transformação que as experiências surrealistas operam. Trata-se, assim, de uma experiência que visa ter um alcance revolucionário. A desordem produtiva que a literatura surrealista aborda se assemelha com os protocolos que Benjamin fez sob efeito de haxixe e mescalina. A iluminação profana relaciona-se com a dialética da embriaguez, na medida em que ambas as ideias remetem a uma nova forma de observar 0 mundo e de transformá-lo. A embriaguez benjaminiana possui várias formas, além das citadas, como a deriva; o próprio pensamento, para o filósofo, já é um narcótico eminente. Assim, Benjamin afirma: "O homem que lê, que pensa, que espera, o flâneur, pertence, do mesmo modo que o fumador de ópio, o sonhador e o ébrio, à galeria dos iluminados. E são iluminados mais profanos. Para não falar da mais terrível de todas as drogas - nós mesmos - que tomamos quando em solidão." (BENJAMIN, 2012, 33)

O poder subversivo do Surrealismo é o de poder nos devolver a embriaguez sóbria que Benjamin discorria sobre. Portanto, para que o Surrealismo seja útil para a vida, é necessário reencontrar o seu elo anárquico perdido e não deixar que este se torne uma arte para agradar aos olhos da burguesia. $O$ poder do Surrealismo estaria na revolta bêbada que ele incita. $A$ embriaguez possui um sentido anárquico: Benjamin diz que a mobilização das forças da embriaguez para a revolução é sua tarefa mais autêntica. Para ela, não é suficiente que, conforme sabemos, um elemento de embriaguez esteja vivo em cada ato revolucionário. "Essa tarefa é idêntica à tarefa anárquica" (BENJAMIN, 2012, 33). Assim, é possível concluir que se trata de uma 
embriaguez de revolta, libertária por excelência, que pretenderia devolver a liberdade para o ser humano.

Segundo André Breton, "foi no negro espelho do Anarquismo que o Surrealismo se reconheceu pela primeira vez"(COELHO, 1990, 41). Para traçar um panorama histórico do movimento e de seu desdobramento político, ainda é fundamental entender as afinidades do Surrealismo com o Anarquismo. 0 conceito de embriaguez benjaminiana não possui apenas um caráter estético, como também elementos anárquicos que serão abordados no decorrer desta exposição. Benjamin formula de forma precisa e dialética que "O domínio da literatura foi explodido de dentro, na medida em que um grupo homogêneo de homens levou a vida literária até os limites extremos do possível" (BENJAMIN, 2012, 22). Essa "explosão", termo usado por Benjamin que agradava muito aos surrealistas e anarquistas, remete aos elementos libertários e revolucionários do movimento, com intuito de transformar as estruturas mentais e mudar a vida dos indivíduos que entram em contato com as obras. Jacques Sorel escreveu no Le monde libertaire no103 em julho de 1964 que "o Surrealismo e o Anarquismo têm mais de um ponto em comum que lhes dão um poder detonador preciso e permanente." Há vários pontos em comum que são facilmente cooptáveis entre os surrealistas e os anarquistas, a revolta, a liberdade, o antipatriotismo, a destruição dos valores conservadores, o desejo da revolução e a contundente aspiração de transformar a vida.

O esclarecimento dos possíveis significados da embriaguez benjaminiana e sua relação com a iluminação profana ilustra como a literatura pode ser transformada conforme este estado de espírito. Benjamin considera o livro Nadja, de André Breton, uma obra muito apropriada para ilustrar alguns traços fundamentais dessa iluminação profana (BENJAMIN, 2012, 24). A obra Nadja traça as experiências surrealistas que indicam um caminho revolucionário que vai além do domínio da literatura. Benjamin descobre, em Nadja , o poder de um anarquismo libertário e insurrecional capaz de abalar a ordem estabelecida das coisas (GATTI, 2009, 87). Essa obra, além de auxiliar a compreensão dos conceitos de iluminação profana e embriaguez, parece também discutir a hipótese de apontar em direção aos vínculos do Surrealismo 
com o Anarquismo. Os ensaios da revista Le Libertaire também ajudam a perceber isso. Os conceitos de embriaguez e iluminação profana se conectam com outros textos de Benjamin, como seus escritos sobre o haxixe; e sua afinidade com o Surrealismo transparece claramente em Rua de Mão Única, já que o livro possui elementos oníricos, reflexões sobre o papel do intelectual, entre outros pontos semelhantes. Em suma, um estudo mais aprofundado acerca do ensaio sobre o Surrealismo suscita uma via de iniciação no pensamento benjaminiano. Há no ensaio de Benjamin uma ambígua empatia com o Anarquismo e a embriaguez que pode ser analisada mais profundamente para uma possível leitura de viés mais libertário. Apesar das interpretações marxistas do ensaio O Surrealismo, o Anarquismo continua sendo um caminho alternativo no pensamento de Walter Benjamin.

A tradição dos oprimidos, como Benjamin observa em suas teses sobre o conceito de História, mostra o esforço para livrar o ser humano dos entraves políticos, espirituais e econômicos que o tem mantido aprisionado ao decorrer do tempo. A luta pela liberdade foi sempre sustentada pelos oprimidos, contra todos aqueles que são detentores dos privilégios. Ao mesmo tempo em que uma classe luta para se libertar da dominação, está também lutando pela liberdade humana; é o anseio dos oprimidos, enquanto, do outro lado, os inimigos da liberdade buscam apenas defender seus privilégios. Há um ponto de encontro primordial entre o Anarquismo e o Surrealismo: a busca pela liberdade. Os anarquistas são os únicos a defender completamente a liberdade, pois buscam a abolição do Estado e de todas as formas de opressão do homem pelo homem. O Surrealismo entraria em cena para transformar as estruturas mentais e para livrar o homem da servidão, da alienação e da reificação. Trata-se de um processo alquímico que transforma as maneiras de pensar e agir do sujeito a partir do seu contato íntimo com o inconsciente, e também o contato com obras de arte que contestam a guerra, o autoritarismo e o nazismo ascendente. Quando o fascismo emergiu, as pessoas que viveram na conjuntura do entre guerras estavam despreparadas, tanto na teoria quanto na prática: assim, os surrealistas pretenderam mobilizar, para a revolução, as energias da embriaguez e da revolta e desprender os oprimidos dos anelos da 
submissão cega às autoridades. Um verdadeiro despertar dos oprimidos. A ameaça mais grave à humanidade não seria apenas a existência de Estados totalitários, mas sim a existência de atitudes que asseguram a vitória de tais autoridades e a dependência de um soberano. Há um campo de batalha em nossa interioridade que necessita de uma disciplina revolucionária para que sejam alteradas as estruturas mentais, em nome da hegemonia popular e da liberdade da humanidade. Em suma, para que o Surrealismo e o Anarquismo sejam pensados em consonância, portanto, é de extrema importância a reflexão sobre o conceito de liberdade.

A filosofia crítica de Walter Benjamin tentou abordar o Surrealismo assimilando-o, em alguns momentos, ao Anarquismo. Um dos pontos de partida de seu ensaio é uma investigação acerca do conceito de liberdade, retirando a aparência superficial de que o Surrealismo trataria tão somente de um movimento "artístico" ou "poético". É importante ressaltar que, para além das conquistas no domínio poético, o Surrealismo também toma partido nas questões sociais. Mais precisamente, trata-se de um movimento profundamente libertário. Unindo a política e a poética, o Surrealismo mostra de que forma a imagem pode desempenhar uma função revolucionária: por exemplo, ao expor o envelhecimento dos objetos e pressentir as energias revolucionárias que transparecem no "antiquado"; por meio das ruínas da modernidade, faz emergir a urgência de um retorno revolucionário, o que gera uma possibilidade de superação da realidade e de redefinição da dimensão política da arte.

Benjamin diz que, para o Surrealismo, nada é mais revelador que as energias revolucionárias que transparecem nos objetos "antiquados". Benjamin aponta que os surrealistas compreenderam melhor do que ninguém a relação entre esses objetos "antiquados" e a Revolução: "Antes desses videntes e intérpretes de sinais, ninguém havia percebido de que modo a miséria, não somente a social como também a arquitetônica, a miséria dos interiores, as coisas escravizadas e escravizantes, transformam-se em niilismo revolucionário." (BENJAMIN, 2012, 25). O truque que Benjamin percebe é que precisamos trocar o olhar histórico sobre esses objetos antiquados e 
envelhecidos por um olhar político, a fim de emergir uma potência revolucionária. Esse é o papel da iluminação profana e da mitologia moderna: trocar o olhar alienado sobre os objetos por um olhar político e crítico.

A perspectiva do ensaio de Benjamin sobre o Surrealismo encara 0 movimento em uma estreita ligação com o Anarquismo. Benjamin relata, em uma carta escrita ao seu amigo Gershom Scholem, que, ao comentar sobre política, já expõe sua posição política: "Falamos também um bocado de política e socialismo; sobre o último, tínhamos grandes reservas, bem como sobre a posição do indivíduo na sua central realização. Para nós, o anarquismo teórico ainda era a resposta mais sensível à política." (SCHOLEM, 2008, 91). O jovem Benjamin, na busca de uma alternativa ao capitalismo, inspirou-se no pensador anarquista Gustav Landauer, teórico anarquista alemão do fim do século XIX que inspirou os textos de Benjamin. Em um primeiro momento, Benjamin possui afinidades revolucionárias que se orientam em direção ao Anarquismo e anarcossindicalismo; é após ler História e Consciência de Classe (1923), de Lukács, que Benjamin muda seu pensamento político.

O importante é ressaltar que o Anarquismo sempre foi uma via possível no pensamento benjaminiano, o que aparece de forma contundente em seu ensaio sobre o Surrealismo. Se for a partir da imaginação que o Surrealismo pretende exprimir o funcionamento real do pensamento, na ausência da coerção exercida pela razão, e sem preocupações estéticas, então a sua escolha política-ideológica passa a se alinhar com a "utopia" libertária do Anarquismo. Pois ambos, Surrealismo e Anarquismo, criticam a tríade "EstadoTrabalho-Religião" e propõem a urgência de uma revisão das doutrinas, com o intuito de fazer emergir uma teoria que seja capaz de impulsionar uma revolução social. Marie Dominique Massoni, principal inspiradora de tais iniciativas, escreveu na apresentação de uma exposição, em 1996: "Insubmissão: a imaginação ateia fogo à pólvora. Sem ela, nenhuma revolta se mantém." (LÖWY, 2002, 102). Tanto os anarquistas como os surrealistas condenam os regimes políticos em vigor: sistemas capitalistas, democracias burguesas, totalitarismos. Ambos, Anarquismo e Surrealismo, pregam a ação autônoma dos trabalhadores. 
No manifesto do Surrealismo de 1924, Breton escreve: "A palavra liberdade é a única que ainda me exalta(...) Ela responde, sem dúvida alguma, a minha única aspiração legítima." (BRETON, 2001, 17). Ao analisar com ênfase essa declaração, pode-se compreender melhor a estreita ligação dos surrealistas com o Anarquismo. Os libertários defendem a primazia do julgamento e da liberdade dos indivíduos e são contra todo aparelhamento de repressão do Estado e de autoridades. Sendo assim, a liberdade é um conceito chave para entender as afinidades revolucionárias do Surrealismo. Ao tratar desse tema, é de suma importância ater-se às suas características políticas e emancipatórias. Benjamin utiliza o conceito de iluminação profana para abordar a transformação da experiência, e logo indica o papel do intelectual na transformação da sociedade. Assim, a revolução não pode ser desvelada com tranquilidade, delicadeza ou amabilidade; mas é um motim, movimento de embriaguez, ato violento por meio do qual uma classe derruba outra. A embriaguez que Benjamin trata em seu ensaio é uma embriaguez de revolta, e Benjamin diz que essa tarefa é idêntica à tarefa anárquica. Associando a liberdade à revolta, Mikhail Bakunin em seu célebre livro intitulado Deus e o Estado, começa seu discurso da seguinte forma:

Três elementos ou três princípios fundamentais constituem, na
história, as condições essenciais de todo desenvolvimento humano,
coletivo ou individual: $1^{\circ}$, a animalidade humana; $2^{\circ}$, o pensamento;
$3^{\circ}$ a revolta. À primeira corresponde propriamente a economia social
e privada; à segunda, a ciência; à terceira, a liberdade (BAKUNIN,
2011, p.37).

A revolta é uma palavra plebeia que possui significados numerosos, desde segunda volta até confusão e mistura de uma coisa com outra. É associada à desordem e ao desregramento. A revolta dissolve as distinções em uma massa informe; é o retorno à natureza, à igualdade. E, para Bakunin, "só sou verdadeiramente livre quando todos os seres humanos que me cercam, homens e mulheres, forem igualmente livres". A liberdade só existe junto à igualdade, e, para alcançar esse fim, a revolta é fundamental. O Surrealismo mostra que é importante manter o espírito insatisfeito que semeia a confusão para derrubar a ordem burguesa vigente. Nadja é um livro apropriado para ilustrar a iluminação profana, pois Breton o descreve como um "livre à porte 
battante", ou um "livro de portas batentes". Trata-se de uma experiência semelhante a de estar em um motim, onde as vias de se percorrer as ruas da cidade são ditadas pelos tiros, bombas de gás, coquetéis molotov, e essa também seria, então, uma forma de embriaguez.

No livro Nadja, Breton narra o espírito libertário no seguinte fragmento:

\begin{abstract}
Odeio com todas as forças essa servidão que querem me fazer aceitar. Lamento que o homem esteja condenado a ela, que em geral não possa se ver livre dela, mas não é a dureza da pena que vai me dispor em seu favor: é, e só poderia ser, a veemência de seu protesto. Sei que no forno de uma fábrica, ou diante de uma dessas máquinas inexoráveis que impõem 0 dia inteiro, com alguns segundos de intervalo, a repetição do mesmo gesto, ou em qualquer outro lugar, sob as ordens mais inaceitáveis, ou na prisão, ou diante de um pelotão de fuzilamento, mesmo assim podemos nos sentir livres, mas não é o martírio que sofremos que cria essa liberdade. Eu quero que a liberdade seja uma permanente quebra de grilhões: contudo, para que essa quebra seja possível, constantemente possível, é necessário que as correntes não nos esmaguem, como fazem com muitos daqueles a quem se refere. Mas a liberdade também é, e humanamente talvez ainda mais, uma sequência de passos mais ou menos longa, porém maravilhosa, que o homem pode dar fora dos grilhões (BRETON, 2007, p. 68-69).
\end{abstract}

O Anarquismo é uma ideologia que emerge das lutas dos grupos marginalizados no final da década de XIX. Sua teoria e prática buscam uma sociedade igualitária em oposição ao sistema capitalista. O Surrealismo, portanto, é historicamente semelhante em suas ambições por liberdade. Piotr Kropotkin, grande teórico do Anarquismo, em O princípio anarquista, escreve que "os anarquistas são os únicos a defender por inteiro o princípio da liberdade."

\begin{abstract}
"Observai à vossa volta. O que restou de todos os partidos que outrora se anunciaram como partidos eminentemente revolucionários? - Só dois partidos estão em oposição: o partido da coerção e o partido da liberdade; os anarquistas, e, contra eles, todos os outros partidos, qualquer que seja sua etiqueta. É que, contra todos esses partidos, os anarquistas são os únicos a defender por inteiro o princípio da liberdade. Todos os outros se gabam de tornar a humanidade feliz mudando ou suavizando a forma do açoite. Se eles gritam 'abaixo a corda de cânhamo da forca', é para substituí-la pelo cordão de seda, aplicado no dorso. Sem açoite, sem coerção, de um modo ou de outro, sem o açoite do salário ou da fome, sem aquele do juiz ou do policial, sem aquele da punição sob uma forma ou outra, eles não podem conceber a sociedade. Só nós ousamos afirmar que punição, polícia, juiz, salário e fome nunca foram, e jamais serão, um elemento de progresso; e se há progresso sob um regime que reconhece esses instrumentos de coerção, esse progresso é conquistado contra esses instrumentos, e não por eles." (KROPOTKIN, 2012, p.36)
\end{abstract}

Bacharel em Filosofia e graduando em licenciatura em Filosofia pela UNIFESP.

Pesquisador financiado pela CNPq. Brasileiro, residente em São Paulo-SP. Email: matheus.silveira.st@gmail.com 
Para Adorno, a obra de arte vanguardista é a única expressão autêntica possível do atual estado do mundo. O autor considera a obra de arte vanguardista como a "expressão historicamente necessária da alienação na sociedade do capitalismo tardio" (BÜRGER, 2008, 170). As obras de arte vanguardistas desnudam as contradições da sociedade do presente, e as categorias das teorias estéticas são radicalmente históricas, segundo Adorno. Para ele, as obra de arte são:

\footnotetext{
"a historiografia inconsciente da essência e da excrescência históricas" [...] compreende a arte vanguardista como protesto radical de oposição a toda e qualquer falsa reconciliação com o existente, sendo, por conseguinte, a única forma de arte historicamente legítima. (BÜRGUER, 2008, 172-3)
}

A aporia que aparece ao se pensar o efeito social das obras e sobre a ciência materialista da literatura é o efeito político das obras de arte vanguardistas na esfera da práxis vital. Em outras palavras, seria então 0 caráter de protesto das obras surrealistas inócuo em relação às reais forças de oposição que trabalham na superação do capitalismo, abstrato e sem perspectiva histórica? Ou se trataria isso de uma oposição a toda e qualquer falsa reconciliação com o existente, sendo a única forma de arte historicamente legítima? Esse é o debate que é posto ao se pensar a vanguarda e 0 engajamento. Por sua rejeição revolucionária da sociedade capitalista, o Surrealismo coincide historicamente com o pensamento libertário, ao nível político. Os surrealistas tinham a pretensão da criação de uma "organização comum dos artistas revolucionários contra o fascismo, o stalinismo e o sistema capitalista: a Federação Internacional pela Arte Revolucionária Independente" (LÖWY, 2002, 74).

A função histórica do Surrealismo, portanto, seria a oposição às formas alienadas de existência a partir de uma revolução do espírito, que seria alcançada pela iluminação profana. As obras de Benjamin possuem um teor libertário que realmente precisa ser observado com mais atenção. Em suas teses sobre o conceito de História, é possível observar o espírito libertário que Benjamin percorre em seus escritos ao longo de toda a vida. Benjamin enfatiza 
que "o 'estado de exceção' ( 'Ausnahmezustand' ) em que vivemos é a regra. Precisamos construir um conceito de história que corresponda a esse ensinamento (...) com isso nossa posição ficará melhor na luta contra 0 fascismo" (BENJAMIN, 2012, 245). A posição libertária e antifascista do autor é nítida em seus escritos e, para construir esse conceito que nos auxiliará na luta contra o fascismo, é de extrema importância manter sempre aceso o transe bêbado da revolta que era exaltado pelos surrealistas.

\section{CONCLUSÃO}

A síntese anarquista-surrealista está em declínio. A proposta surrealista consiste em, a partir do terreno sensível, transformar as estruturas mentais. É preciso reencontrar uma poética e uma ética que sejam capazes de operar essa transformação, e que essas obras estejam de acordo com as expressões e os anseios das massas em nome da liberdade. Criar uma sociedade sem classes, sem Estado, em que as aspirações humanas possam se realizar e que o ser humano possa a vir dispor inteiramente de si mesmo é um objetivo a ser almejado. O Surrealismo precisa sair da condição de arte palatável para os olhos da burguesia e reencontrar o transe bêbado da revolta. É necessário devolver o maravilhoso para o cotidiano e reestabelecer no coração da vida humana o anseio pela liberdade. É preciso relembrar a história do movimento, história essa de oposição à sociedade capitalista, e não se esquecer de sua veia e suas raízes libertárias, mobilizando esses conceitos e ideias para uma ação que transforme a sociedade.

\section{REFERÊNCIAS}

ARAGON, L. O Camponês de Paris. Rio de Janeiro: Editora Imago, 1996.

BENJAMIN, W. "O Surrealismo”. In_: Obras Escolhidas I - Magia e Técnica, Arte e Política. Tradução Sérgio Paulo Rouanet. São Paulo: Editora Brasiliense, 2012.

Brasiliense, 2012.

Obras Escolhidas II. Rua de Mão Única . São Paulo:

Bacharel em Filosofia e graduando em licenciatura em Filosofia pela UNIFESP. Pesquisador financiado pela CNPq. Brasileiro, residente em São Paulo-SP. Email: 
Sobre o haxixe e outras drogas. Tradução João Barrento.

Belo Horizonte: Autêntica,2013.

Baudelaire e a modernidade. Trad. João Barrento, São Paulo:

Autêntica, 2015.

BÜRGER, P. Teoria da Vanguarda. Tradução de José Pedro Antunes. São

Paulo: Editora Cosac Naify, 2012.

BRETON, A. Nadja. Tradução: Ivo Barroso, São Paulo: Cosac Naify, 2007.

Manifestos do Surrealismo. Rio de Janeiro: Nau, 2001.

COELHO, P. A. Surrealismo e anarquismo: "bilhetes surrealistas" de Le

Libertaire. São Paulo: Editora Imaginário, 1990.

GATTI, L. Walter Benjamin e o Surrealismo: escrita e iluminação profana, Artefilosofia $\mathrm{n}^{\circ} 6$.

GUINSBURG, J.; LEIRNER, S. (Orgs.). O Surrealismo . São Paulo: Perspectiva, 2008.

KROPOTKIN, P. O princípio anarquista e outros ensaios. Trad. Plínio Coelho, São Paulo: Editora Hedra, 2007.

LÖWY, M. A estrela da manhã. Tradução Eliana Aguiar, Rio de janeiro: Civilização Brasileira, 2002.

LÖWY, M.; SAYRE, R. Revolta e melancolia: o romantismo na contracorrente da modernidade. Trad. Nair Fonseca. São Paulo: Boitempo, 2015. 